\title{
Changes in colour and phenolic composition during the early stages of maturation of port in wood, stainless steel and glass
}

Keywords: port; maturation; colour; phenolic composition; oxygen; principal component analysis

\author{
Peter Ho,* Maria da Conceição M Silva and Timothy A Hogg \\ Escola Superior de Biotecnologia, Universidade Católica Portuguesa, Rua Dr António Bernardino de Almeida, 4200-072 Porto, Portugal
}

\begin{abstract}
Differences in colour and phenolic composition during the maturation of port in oak wood, stainless steel and glass were examined for a period of 311 days at $18^{\circ} \mathrm{C}$. Principal component analysis (PCA) was used in variable selection, data reduction and data analysis. Nine out of 13 colour and phenolic variables were heavily loaded on PC1 (76.1\% of explained variance), and a plot of PC1 scores versus maturation time showed differences in colour and anthocyanins between ports matured in different containers. Ports matured in oak casks developed at a faster rate than the other ports. Total phenolics remained fairly constant in all ports, as monomeric anthocyanins were rapidly depleted during the time of maturation. Polymeric pigments formed during maturation contributed to increases in colour density, hue and the rate of browning. Differences in redox potential between wood matured ports and non-wood matured ports indicated that there were differences in dissolved oxygen which could have affected the maturation rate of these wines.
\end{abstract}

\section{INTRODUCTION}

During the maturation of wine, anthocyanins and other phenolic compounds such as flavanols participate in various chemical reactions which result in changes in wine colour. ${ }^{1-5}$ These changes in colour are due to a decrease in the concentration of monomeric anthocyanins and the progressive formation of polymeric pigments. ${ }^{6-12}$ The purple-red colour of a young port changes towards a tawny or orange-brown colour as it matures. ${ }^{13,14}$ These changes in visible colour can be observed by changes in the wavelength and intensity of maximum absorbance. ${ }^{15-17}$ However, the colour of port also increases markedly during the initial months of aging, reaching a maximum before it begins to decline. ${ }^{2}$ Both these changes in the colour of port during maturation may result from the formation of malvidin-derived pigments known as vitisins. ${ }^{11} \mathrm{~A}$ substantial amount of information is known about colour, anthocyanins, polymeric pigments and their changes during the early maturation of port. ${ }^{2,6,18,19}$ However, these studies only examined these changes in ports stored in sealed glass jars with a limited headspace. There is little information about changes in colour and phenolic composition in ports matured in oak casks and about changes occurring during maturation. ${ }^{20,21}$

Numerous different methods for characterising the colour of wine have been developed based on either spectrophotometry ${ }^{22-25}$ or tristimulus colorime-

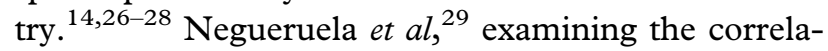
tion between colorimetric indices and CIE colour space parameters, concluded that Glories' index of colour intensity and Sudraud's index of tint were the best indices for quality control of wine colour. However, this and other studies only examined a few of the many spectral parameters that could be used to measure and monitor colour and composition changes during wine maturation. ${ }^{29-31}$

In a previous paper, relationships among 26 variables describing changes in the colour and phenolic composition of port during maturation were examined by principal component analysis (PCA). ${ }^{32}$ PCA found a number of high correlations between these variables, indicating that many of them were describing similar changes in colour and phenolic composition. The aim of this paper was then to select a reduced set of variables for describing changes in colour and phenolic composition (total phenolics and anthocyanins) during the maturation of port in oak casks, stainless steel tanks and glass jars.

\section{EXPERIMENTAL}

Wines

Port, which was made by a port company from a mixture of red grape varieties (mainly Tinta Roriz,

\footnotetext{
* Correspondence to: Peter Ho, Escola Superior de Biotecnologia, Universidade Católica Portuguesa, Rua Dr António Bernardino de Almeida, 4200-072 Porto, Portugal

E-mail: peter@esb.ucp.pt
} 
Touriga Nacional, Tinta Cão and Tinta Barroca) from the Douro in 1994, had previously been stored in 6001 matured oak casks for a period of 8 months before being used in this experiment. The port was also racked twice (with limited aeration) during that period. The wine had the following characteristics just before being transferred to the respective containers for the experiment: $\mathrm{pH} 3.8,19.2 \%(\mathrm{v} / \mathrm{v})$ alcohol, $120 \mathrm{mg}^{-1}$ total $\mathrm{SO}_{2}$.

\section{Maturation conditions}

Port is normally matured in either 6001 matured oak casks or wooden vats, although concrete vats and stainless steel tanks are also used for some styles of port such as Ruby. Bottle aging is used for Vintage port, and a style of port known as 'garrafeira' is aged in 5 or 101 glass jars. Tawny port is matured in 6001 matured oak casks (also known as 'pipes') for many years under oxidative conditions. Air contact and oxidation of Tawny port occur by forced aeration during racking, and evaporation of wine, resulting in an increase in ullage space, may allow penetration of air through the pores of the staves of the barrel. The experiment aimed at examining the following methods of port maturation: 'Tawny'-type maturation in matured oak casks under oxidative conditions, and 'Ruby'-type maturation in stainless steel tanks and glass jars under limited oxidation.

Three small matured oak casks of approximately 341 capacity were used instead of the standard pipes to accelerate the maturation rate for Tawny port production. Each oak cask was filled with approximately 331 of the 8-month-old port, and a cork was used to seal the bunghole. To ensure a more rapid maturation of port under oxidative conditions, the oak casks were placed in an upright position, allowing the possibility of air entering the ullage space (approximately 11 in each oak cask). Three stainless steel tanks were then filled with approximately 451 of the same 8-month-old port and sealed with a stainless steel cover. The headspace in the steel tanks was estimated to be no more than $200 \mathrm{ml}$, and a rubber seal between the stainless steel cover and each tank, together with the use of bolts, prevented air from entering the tanks when sealed. Finally, two 51 glass jars were filled with approximately 51 of the 8-month-old port and sealed with a cork (headspace less than $20 \mathrm{ml}$ ). All the containers were then place in a controlled temperature room maintained at $18 \pm 2^{\circ} \mathrm{C}$ (no humidity control).

\section{Racking}

Racking is an important part of the oxidative maturation of port. The racking regime can vary between companies and types of wine, but all ports are typically racked three times in the first year, twice in the second and annually thereafter. ${ }^{33}$ The amount of dissolved oxygen taken up by a wine during racking depends on the method used to displace and collect the wine as well as on the aeration technique. ${ }^{34}$ Forced aeration, by pumping the wine first to a small container to induce aeration, is one technique used during the racking of Tawny ports. As it is common practice during the maturation of port to rack a wine at least once a year, some of the ports maturing in oak casks and stainless steel tanks were racked after 224 days of storage. This racking experiment also allowed for a preliminary assessment of the effect of racking with aeration on the maturation of port.

Ports maturing in two oak casks and stainless steel tanks were racked with two different levels of aeration, while ports in the third cask and tank together with both glass jars were not racked to act as controls. Ports from one oak cask and one stainless steel tank were transferred through a pipe into the top of an empty container large enough to contain all the wine. Ports were aerated as they trickled down from the top of the container (forced aeration) A second set was racked, but this time the pipe was placed at the bottom of the empty container, thus reducing the aeration of the wine (limited aeration). The measurement of redox potential has been suggested to determine the frequency of racking and the time of maturation a wine requires. ${ }^{34}$ There also seems to be a good correlation between changes in redox potential and dissolved oxygen during racking, with the redox potential requiring 15-20 days to return to its original level before racking. ${ }^{35}$ A combined redox potential electrode (Ingold Messtechnik AG, Urdorf, Switzerland) connected to a multivoltmeter was used to measure the redox potential in ports matured in oak casks and stainless steel tanks before and after racking at regular intervals. Dissolved oxygen measurements in ports maturing in oak casks and stainless steel tanks were made with a YSI 5739 oxygen probe connected to a YSI 57 dissolved oxygen meter (YSI Inc, Yellow Springs, OH, USA).

\section{Sampling}

Ports in each container were sampled at the beginning of the experiment (day 0) and after 13,34, 77, 110, 198, 255 and 311 days of storage. Approximately $20 \mathrm{ml}$ of port was sampled from four points in each container to make a composite sample. The amount removed was weighed and small glass beads of the same weight were added to each container in order to limit the increase in ullage space from repeated sampling during the experiment.

\section{Colour and phenolic variables}

In total, 26 variables used to describe colour, anthocyanins and total phenolics were calculated from spectrophotometric measurements made at 280,420 , 520 and $620 \mathrm{~nm}$ on each sample according to the methods described below. All samples were measured in either 1 or $10 \mathrm{~mm}$ quartz cells on a Pye Unicam 8620 single-beam spectrophotometer (Unicam Limited, Cambridge, UK), and all absorbance values were corrected to $10 \mathrm{~mm}$ path length. These variables were as follows. 
(a) Sudraud's colour indices: ${ }^{36}$ wine colour density, $\mathrm{CD} 1=A_{420 \mathrm{~nm}}+A_{520 \mathrm{~nm}}$; wine hue or tint, $\mathrm{HUE}=$ $A_{420 \mathrm{~nm}} / A_{520 \mathrm{~nm}}$.

(b) Glories' index of colour density, ${ }^{37} \mathrm{CD} 2=$ $A_{420 \mathrm{~nm}}+A_{520 \mathrm{~nm}}+A_{620 \mathrm{~nm}}$.

(c) Wine colour: ${ }^{38}$ redness, WC $=A_{520 \mathrm{~nm}}$; browning, $\mathrm{BI}=A_{420 \mathrm{~nm}}$.

(d) Anthocyanin and pigment colour: ${ }^{23}$ polymeric pigment colour (after addition of sodium metabisulphite), $\mathrm{PPC}=A_{520 \mathrm{~nm}}^{\mathrm{SO}_{2}}$; total pigment colour (with $1 \mathrm{M} \mathrm{HCl}$ ), WCA $=A_{520 \mathrm{~nm}}^{\mathrm{HCl}}$; anthocyanin colour, $\mathrm{AC}=\mathrm{WC}-\mathrm{PPC}$; anthocyanin colour in acid, $\quad \mathrm{ACA}=\mathrm{WCA}-5 \mathrm{PPC} / 3$; non-coloured anthocyanin, NA $=\mathrm{ACA}-\mathrm{AC}$.

(e) Coloration factors: ${ }^{22}$ degree of ionisation, $\alpha=$ (AC/ ACA) $\times 100 \%$; natural degree of ionisation,

$$
\alpha^{\prime}=\frac{A_{520 \mathrm{~nm}}^{\mathrm{CH}_{3} \mathrm{CHO}}-A_{520 \mathrm{~nm}}^{\mathrm{SO}_{2}}}{A_{520 \mathrm{~nm}}^{\mathrm{HCl}}-\frac{5}{3} A_{520 \mathrm{~nm}}^{\mathrm{SO}_{2}}} \times 100 \%
$$

(f) Modified coloration factors: ${ }^{24}$ degree of pigment coloration (after adjusting wine to $\mathrm{pH} 3.7$ ), $A_{3.7}=\left(A_{520 \mathrm{~nm}} / A_{520 \mathrm{~nm}}^{\mathrm{HCl}}\right) \times 100 \%$; colour synergism factor (by diluting wine 50 -fold with $20 \%$ aqueous ethanol solution saturated with potassium hydrogen tartrate at $\mathrm{pH} 3.7), S_{3.7}=A_{520 \mathrm{~nm}}$ (intact wine) $/ A_{520 \text { nm }}$ (after treatment).

(g) Chemical age indices: ${ }^{23}$ chemical age at wine $\mathrm{pH}$, $\mathrm{CAW}=\mathrm{PPC} / \mathrm{WC}$; chemical age in acid, CAA = 5PPC/3WCA.

(h) Chemical age indices: ${ }^{22,24}$ chemical age index (I), $\mathrm{CA}(\mathrm{I})=A_{520 \mathrm{~nm}}^{\mathrm{SO}_{2}} / A_{520 \mathrm{~nm}}^{\mathrm{CH}_{3} \mathrm{CHO}}$; chemical age index (II), $\mathrm{CA}(\mathrm{II})=A_{520 \mathrm{~nm}}^{\mathrm{SO}_{2}} / A_{520 \mathrm{~nm}}^{\mathrm{HCl}}$; chemical age in$\operatorname{dex}(\mathrm{III}), \mathrm{CA}(\mathrm{III})=A_{520 \mathrm{~nm}}^{\mathrm{HCl}} / A_{280 \mathrm{~nm}}^{\mathrm{HCl}}$.

(i) Total phenolics (absorbance units), ${ }^{22} \mathrm{TP}=$ $A_{280}-4$; total phenolics as gallic acid equivalents $\left(\mathrm{mg} \mathrm{l}^{-1}\right),{ }^{31}$ TPGAE $=29.5 \mathrm{TP}+210$.

(j) Total monomeric anthocyanins $\left(\mathrm{mg} \mathrm{l}^{-1}\right){ }^{22}$ $\mathrm{TAC}=20\left(\mathrm{WC}-\frac{5}{3}\right.$ PPC $)$.

(k) Monomeric anthocyanins, TMA, polymeric anthocyanins, TPA, and total anthocyanins, TAC2, by fractionation using $\mathrm{C}_{18}$ Sep-Pak cartridges. ${ }^{39} \mathrm{~A}$ $2 \mathrm{ml}$ aliquot of wine was passed through a $\mathrm{C}_{18}$ SepPak cartridge that had been preconditioned for neutral phenolics by sequentially passing $2 \mathrm{ml}$ of methanol and distilled water dropwise. ${ }^{40}$ Monomeric anthocyanins (fraction I) were removed by passing through $2 \mathrm{ml}$ of $16 \%$ acetonitrile, and polymeric anthocyanins (fraction II) were eluted with $2 \mathrm{ml}$ of methanol. Each fraction was then measured at $520 \mathrm{~nm},{ }^{41}$ TMA or TPA $=\left(A_{520 \mathrm{~nm}^{\prime}}\right.$ $\in) \times 529 \times$ dilution factor (expressed as malvidin3 -glucoside with a molecular mass of 529 and a molar absorptivity $(\in)$ of $\left.28000 \mathrm{M}^{-1} \mathrm{~cm}^{-1}\right)$. The summation of the two fractions gave the total anthocyanin content, TAC2. All values were in $\mathrm{mg}^{-1}$.

(1) Total anthocyanin content $\left(\mathrm{mg} \mathrm{l}^{-1}\right)$ by directly measuring a wine sample (without fractionation), ${ }^{41}$ TAC3.
The above spectral measurement also permitted the measurement of free $\mathrm{SO}_{2}$ according to the methods of Somers and Evans. ${ }^{22}$

\section{Data analysis}

Multiple imputation

The multivariate data matrix collected was found to contain a number of missing values, as certain measurements were unintentionally missed out. In order to preserve the structure of the data matrix (without having to remove variables or cases that contain missing values), missing values were determined by multiple imputation. Multiple imputation handles missing values in a data matrix by generating $m>1$ plausible missing values, thus producing $m$ apparently complete data matrices which can then be analysed by the complete data methods. ${ }^{42}$ After analysing each complete data matrix separately, the results are combined and standard errors of the estimated parameters can be calculated that reflect missing data uncertainty. The program NORM, ${ }^{43}$ which can be freely downloaded as a stand-alone program or as libaries for S-PLUS and R, was used to perform multiple imputation under a multivariate normal model. NORM was used to firstly calculate an initial estimate of missing values using the expectation maximization (EM) algorithm and then followed by data augmentation (DA) to generate five complete data matrices. These algorithms and the methods used to assess their convergence, together with complete details of parameters used to generate imputed values, have been described in detail in a previous paper. ${ }^{32}$

\section{Principal component analysis of reduced variable data matrix}

Each of the five complete data matrices (with only 13 variables) was analysed separately. PCA by singular value decomposition (SVD) after standardisation of the data matrix (using a correlation matrix) was conducted using the multiv library from the statistical program $R,{ }^{44}$ a GNU S-clone freely available for downloading at http://www.r-project.org. Each set of analyses produced a matrix of PC scores and loadings. These estimated values were combined and the standard error of the mean (SEM) for each value in the scores and loadings matrices was calculated.

\section{RESULTS AND DISCUSSION Changes in chemical and environmental factors during maturation}

Before examining the differences in colour and phenolic composition (total anthocyanins and total phenolics), it was important to consider how some chemical and environmental factors would have affected these differences. $\mathrm{pH}$ is one factor which should be measured, as large differences in $\mathrm{pH}$ can affect many variables such as colour density, hue, browning, chemical age, degree of pigment coloration and polymeric pigment colour. ${ }^{45-47}$ Differences in $\mathrm{pH}$ 
have also been shown to affect the rate of loss of malvin-3-glucoside and the formation of polymeric pigments. ${ }^{48}$ At the start of the experiment, all ports had the same $\mathrm{pH}$ value of approximately 3.8. This value stayed fairly constant throughout the first 198 days of storage, with a $\mathrm{pH}$ deviation of \pm 0.1 observed occasionally in some of the ports. By 255 days of storage, all ports stored in stainless steel tanks and glass jars still had a $\mathrm{pH}$ value of 3.8 , while those in oak casks dropped to $\mathrm{pH}$ 3.7. Final measurements at the end of 311 days of storage gave a value of $\mathrm{pH} 3.6$ for ports matured in stainless steel tanks and glass jars, with ports matured in oak casks at $\mathrm{pH} 3.5$. These small differences in $\mathrm{pH}$ measured at each sampling time, which were no greater than 0.1 , would have probably caused only marginal differences in colour between ports. Model studies with five different anthocyanins have shown that only slight differences in chromatic properties such as brightness, chroma, purity and hue occurred within the $\mathrm{pH}$ range 3.5-4. ${ }^{49}$

The amount of sulphur dioxide $\left(\mathrm{SO}_{2}\right)$ present in a wine also plays an important role, with increasing amounts added resulting in a reduction in the loss of anthocyanins and procyanidins and the subsequent formation of polymeric pigments..$^{3,8,45,50}$ It has also been found that the level of free $\mathrm{SO}_{2}$ has a greater influence than $\mathrm{pH}$ on pigment equilibria and the degree of coloration in young red wines. ${ }^{51}$ The amount of free $\mathrm{SO}_{2}$ (spectral method) at the beginning of storage was estimated to be $0.7-0.8 \mathrm{mg} \mathrm{l}^{-1}$ for ports stored in stainless steel tanks and glass jars and $0.5 \mathrm{mg}^{-1}$ for those stored in the oak casks. Red wines with initial levels of free $\mathrm{SO}_{2}$ (spectral method) of $0-4.4 \mathrm{mg} \mathrm{l}^{-1}$ (mean of 1.3) showed similar values for the age index $\left(A_{520 \mathrm{~nm}}^{\mathrm{SO}_{2}} / A_{520 \mathrm{~nm}}^{\mathrm{CH}_{3} \mathrm{CHO}}\right)$ after aging for 1 year at $20^{\circ} \mathrm{C}{ }^{52}$ Those results suggest that a variation in free $\mathrm{SO}_{2}$ at these low levels may only cause a slight difference in colour composition between red wines during maturation. During storage, free $\mathrm{SO}_{2}$ varied between 0 and $1.5 \mathrm{mg}^{-1}$ for ports stored in stainless steel tanks and glass jars and between 0 and $0.7 \mathrm{mg}^{-1}$ for those stored in oak casks. The variation in free $\mathrm{SO}_{2}$ could have been due to changes in the equilibrium between bound $\mathrm{SO}_{2}$ forms with various wine components such as acetaldehyde, anthocyanins, pyruvic acid and $\alpha$-keto glutaric acid. ${ }^{53}$ Although acetaldehyde is an important factor in colour development and the formation of polymeric pigments during maturation, ${ }^{2,3,54}$ its concentration in each port was not determined. Hence the effect of acetaldehyde concentration on the maturation of port in the different containers could not be assessed. It was assumed that initial levels of free acetaldehyde would probably have been similar in all ports at the start of maturation.

However, the single most important factor during the maturation of these ports would have been the amount of dissolved oxygen. Differences in the amount of dissolved oxygen in each port depended on the following: the initial amount of oxygen in the ullage space or headspace in each container; the amount of residual oxygen remaining in the ullage space or headspace in each container throughout maturation; and the amount of oxygen produced by racking. At the start of maturation, ports in oak casks were exposed to the highest amount of oxygen from the ullage space of 11 , followed by those in stainless steel tanks with a headspace of approximately $200 \mathrm{ml}$, and finally those in the glass jars with less than $20 \mathrm{ml}$ of headspace. The amount of oxygen remaining in the ullage space in each oak cask depended on the rate of consumption of oxygen by the port and on the amount of oxygen that was allowed to enter the ullage space during maturation. Oxygen could have entered the ullage space through the cork stopper and possibly through the parts of the staves that were not in contact with any port. The cork stopper in the glass jars would also have not prevented oxygen from entering the headspace. However, a limited amount of oxygen would have entered the headspace in the stainless steel tanks. Higher redox potential values, taken before racking after 200 days, were found in ports matured in oak casks, indicating a more oxidative environment or exposure to greater amounts of oxygen compared to those ports matured in stainless steel tanks (see Table 3). This difference in redox potential between ports matured in oak casks and those matured in stainless steel tanks was observed throughout the maturation of these ports. Measurements made 15 months after racking showed that the higher redox potential values in ports matured in oak casks were associated with a higher dissolved oxygen content in these wines (see Table 3). Volume losses from evaporation and racking would also have accounted for changes in the oxygen concentration, as shown by increases in the ullage space in the oak casks and to a lesser degree in the headspace in the stainless steel tanks and glass jars during the maturation of these ports (see Table 3). Volume losses due to evaporation in ports matured in oak casks were estimated to be approximately 3-7.6\% after about 220 days, resulting an increase in ullage space of 1-2.51. Racking accounted for a loss in volume of $0.5-11$ in ports matured in oak casks and $0.06-0.161$ in ports matured in stainless steel tanks. More importantly, racking would have affected the dissolved oxygen. However, neither of the two racking methods had a significant effect on the redox potential in ports matured in oak casks. Measurements taken 1 month after racking showed only a slight increase in redox potential in the port racked with forced aeration (FAR) and an insignificant decrease in redox potential in the port racked with limited aeration (see Table 3 ). The port that was not racked had similar redox potential values to those of the racked ports both before and 1, 2 and 3 months after racking. This suggests that the dissolved oxygen in ports matured in oak casks probably returned to its initial level within 1 month after racking. However, both racking methods had a greater effect on the redox potential in ports matured in stainless steel tanks. Initial values before racking were significantly lower than those in ports 
Table 1. Selection of variables for describing changes in colour and phenolic compounds

\begin{tabular}{lll}
\hline Wine attribute & $\begin{array}{l}\text { Variable } \\
\text { selected }\end{array}$ & $\begin{array}{r}\text { Variables } \\
\text { dropped }\end{array}$ \\
\hline Wine colour/colour density & CD2 & CD1, WC, WCA \\
Hue & HUE & \\
Degree of coloration & $A_{3.7}$ & $\alpha, \alpha^{\prime}$ \\
Colour synergism & $S_{3.7}$ & \\
Total polymeric pigments & PPC & \\
Total monomeric anthocyanins & TMA & AC, ACA, NA, TAC \\
Total polymeric anthocyanins & TPA & \\
Total anthocyanins & TAC2 & TAC3 \\
Browning & BI & \\
Total phenolics & TPGAE & TP \\
Age index (I) & CA(I) & CAW \\
Age index (II) & CA(II) & CAA \\
Age index (III) & CA(III) & \\
\hline
\end{tabular}

matured in oak casks, indicating a lower amount of dissolved oxygen. Under the same racking regimes employed for ports matured in oak casks, a significant increase in redox potential was found in both ports 1 month after racking (see Table 3). However, redox potential values were quite similar between the racked ports and the port that was not racked after 2 and 3 months after racking. These results show that racking with aeration results in only a temporary increase in dissolved oxygen. Therefore its importance as a means of altering the dissolved oxygen content in a wine depends on the frequency of racking, the wine's oxidation state and the initial dissolved oxygen content before racking. Normal practices of racking with aeration up to three times in the first year would likely have an important effect on the early maturation of port.

\section{Principal component analysis using a reduced number of variables for describing changes in colour and phenolic composition}

In the previous paper, ${ }^{32}$ many of the 26 variables were found to be highly correlated, ie variables that were highly correlated were positioned beside each other on loadings plots from a principal component analysis. For example, colour density could be equally described by Sudraud's colour density index (CD1) or Glories' index (CD2). Therefore a reduced set of variables could be chosen which would describe the same information as the original 26 variables. The 26 variables can be grouped according to the attribute which they measure. Hence variables which described the 13 attributes (Table 1) were chosen based on their correlation with other variables and on suggestions made by Somers and Vérette. ${ }^{24}$ For example, both Glories' index (CD2) and Sudraud's index (CD1) were used to measure colour density. The difference between these two indices is the additional measurement of the absorbance at $620 \mathrm{~nm}$ for Glories' index. Since a young wine can show a significant absorbance at that wavelength, Glories' index was chosen instead of Sudraud's index. For anthocyanins, the fractionation method which allowed the determination of monomeric (TMA), polymeric (TPA) and total (TAC2) anthocyanins was chosen instead of the other two anthocyanin parameters (TAC and TAC3). The five imputed data matrices, now with only 13 variables, were then reanalysed by PCA. Selection of the appropriate number of principal components was based on the rule of eigenvalues greater than 1.0, the scree plot and the proportion of variance explained. ${ }^{55}$ The first three PCs, which accounted for about $93 \%$ of the explained variance (Table 2), could be used to show changes in colour and phenolic composition during the maturation of port.

Loadings plots (Figs 1 and 2) for the first two principal components (PC1 vs PC2) and the first and third principal components (PC1 vs PC3) showed almost identical patterns to the loadings plots from the original 26-variable PC model. ${ }^{32}$ Standard errors of the mean for the combined estimates of the loadings matrix and scores matrix were also similar, typically less than 0.02. The first three PCs could be used to explain changes in colour and phenolic composition (total phenolics and anthocyanins) during the maturation of port. Changes in most of the 13 variables were described mainly by the first principal component (PC1) (76.1\% explained variance). Variables describing colour, such as wine colour (CD2) and browning (BI), had high positive loadings on PC1. The variable HUE was the only colour variable with a lower positive loading on PC1. Variables showing the contribution of wine pigments to colour, namely chemical age indices

Table 2. Estimated average eigenvalues and the proportion of variance from imputed data matrices

\begin{tabular}{|c|c|c|c|c|c|c|c|c|}
\hline \multirow[b]{2}{*}{$P C$} & \multicolumn{4}{|c|}{ Original variable set } & \multicolumn{4}{|c|}{ Reduced variable set } \\
\hline & Eigenvalue & $S E M^{a}$ & $\%$ variance & $\%$ cumulative & Eigenvalue & SEM ${ }^{a}$ & $\%$ variance & $\%$ cumulative \\
\hline 1 & 20.5312 & 0.0535 & 79.63 & 79.63 & 9.8407 & 0.0504 & 76.11 & 76.11 \\
\hline 2 & 2.2206 & 0.0118 & 8.61 & 88.24 & 1.2322 & 0.0185 & 9.53 & 85.64 \\
\hline 3 & 1.3007 & 0.0245 & 5.04 & 93.29 & 0.9430 & 0.0178 & 7.29 & 92.93 \\
\hline 4 & 0.9724 & 0.0129 & 3.77 & 97.06 & 0.5629 & 0.0029 & 4.35 & 97.29 \\
\hline 5 & 0.4416 & 0.0130 & 1.71 & 98.77 & 0.1981 & 0.0145 & 1.53 & 98.82 \\
\hline 6 & 0.1747 & 0.0031 & 0.68 & 99.45 & 0.0871 & 0.0062 & 0.67 & 99.49 \\
\hline 7 & 0.1415 & 0.0068 & 0.55 & 100 & 0.0654 & 0.0052 & 0.51 & 100 \\
\hline
\end{tabular}

a Standard error of the mean of eigenvalues, $n=5$. 

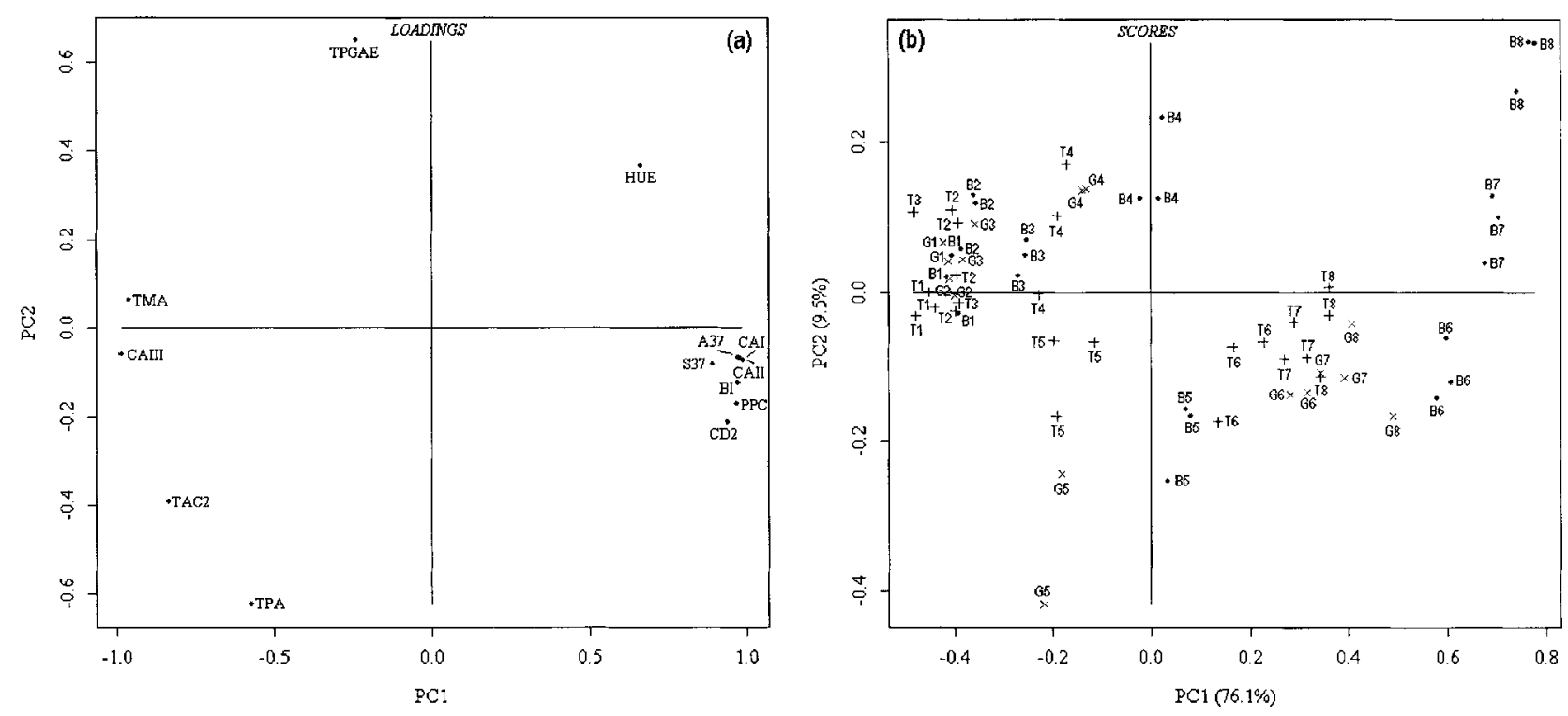

Figure 1. Principal component analysis plots (PC1 vs PC2) for the maturation of port: (a) loadings plot; (b) scores plot. Legends: B, oak casks; T, stainless steel tanks; G, glass jars. Numbers indicate time of aging (days): 1, initial time; 2, 13; 3, 34; 4, 77; 5, 110; 6, 198; 7, $255 ; 8,311$.

(CA(I) and $\mathrm{CA}(\mathrm{II})$ ) and polymeric pigment colour (PPC), also had high positive loadings on PC1, as did the degree of pigment coloration $\left(A_{3.7}\right)$ and colour synergism $\left(S_{3.7}\right)$. The degree of pigment coloration gives a measure of pigment equilibria, whereas colour synergism is a measure of self-association and copigmentation effects in wine. ${ }^{24}$ A plot of PC1 scores versus maturation time could be used to measure changes in colour during the maturation of these ports (Fig 3(a)). High negative loadings on PC1 found for total monomeric anthocyanins (TMA) and total anthocyanins (TAC2) were well correlated to the chemical index CA(III). CA(III) is considered to be the most objective index of the change in phenolic composition, as it shows the decreasing presence of pH-responsive pigments during maturation. ${ }^{24}$ TMA and to a lesser extent TAC2 decreased in concentra- tion during maturation. This was because TAC2 was the sum of monomeric (TMA) and polymeric (TPA) anthocyanins and hence was situated in between these variables in both loadings plots (Figs 1 and 2). However, polymeric pigment colour (PPC) and polymeric anthocyanins (TPA) were not well correlated. PPC measures only the amount of polymeric pigments that are resistant to bleaching by $\mathrm{SO}_{2}$, whereas TPA should account for polymeric pigments giving a contribution to the absorbance at $520 \mathrm{~nm}$ regardless of their resistance to $\mathrm{SO}_{2}$ bleaching. Some polymeric pigments such as vitisin $\mathrm{B}$ can be bleached by up to $50 \%$ by $\mathrm{SO}_{2}$, ${ }^{11}$ so PPC may not fully account for the formation of polymeric pigments that are not completely resistant to $\mathrm{SO}_{2}$. Total phenolics (TPGAE) was very poorly loaded on PC1 but had higher positive loadings on PC2 and PC3 (almost
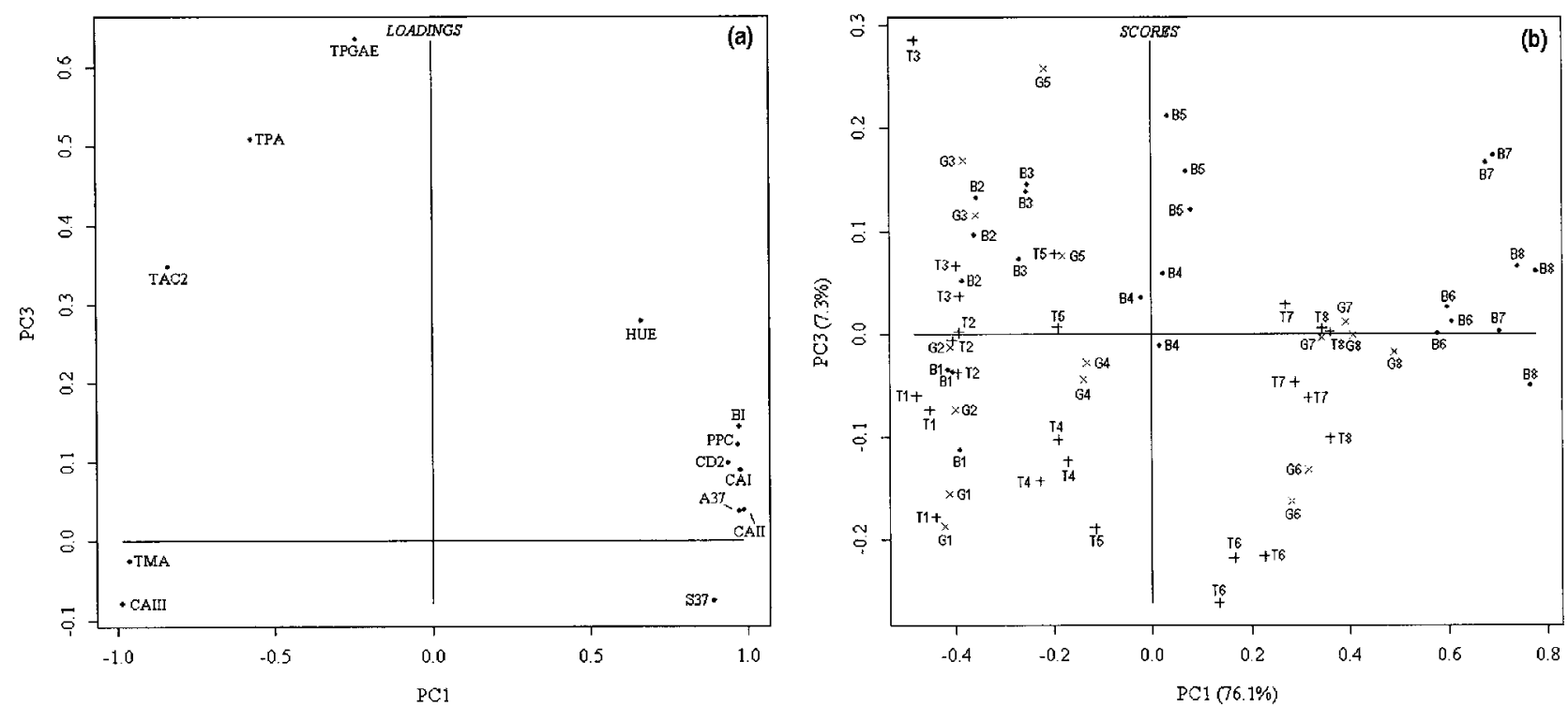

Figure 2. Principal component analysis plots (PC1 vs PC3): (a) loadings plot; (b) scores plot. Legends are the same as for Fig 1. 

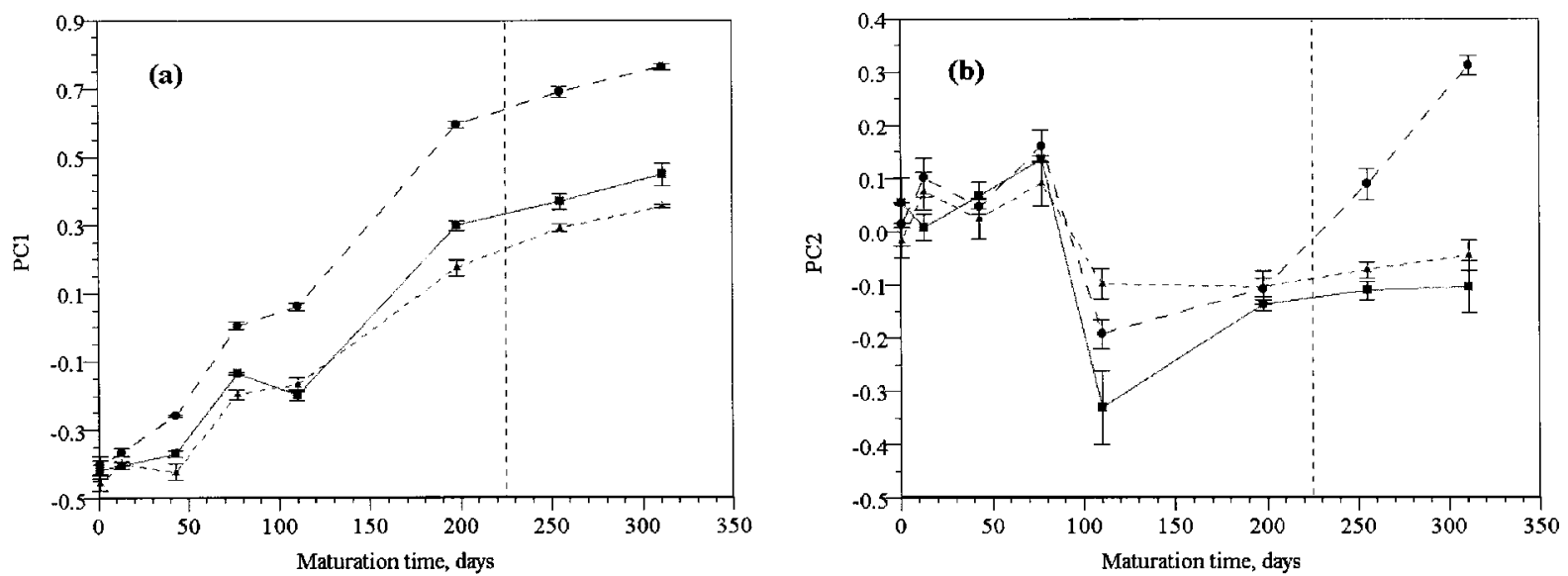

Figure 3. Changes in principal component scores for ports matured in oak (circles), stainless steel (triangles) and glass (squares): (a) PC1 vs maturation time; (b) PC2 vs maturation time. Error bars show the $95 \%$ confidence interval of the mean.

equal contributions on these PCs). Total phenolics stays relatively constant with perhaps a slight decrease during the maturation of port, ie a loading value of about -0.24 on PC1. Changes in total phenolics during maturation can be partially explained by plotting PC2 scores versus maturation time (Figure 3(b)). Ports with higher PC2 scores seem to have higher values of total phenolics. However, the large increase in PC2 scores between ports matured in oak casks and those matured in either stainless steel tanks or glass jars after racking might be more related to changes in hue (Fig 4(a)).

\section{Changes in colour and phenolic composition of port during maturation in different containers}

Browning (BI), colour density (CD2) and polymeric pigment colour (PPC) generally increased in all ports during maturation (Figs 4(b), 5(a) and 5(b) respectively). However, BI, CD2 and PPC reached their highest values at 198 days for ports matured in oak casks, before decreasing. Browning, colour density and polymeric pigment colour were almost the same in all ports by 311 days of maturation. On the other hand, HUE remained fairly constant throughout the maturation of ports in stainless steel and glass. A sharp increase in the change in hue was observed for ports matured in oak casks after 250 days of maturation (Fig 4(a)). This increase was likely due to a much greater decrease in red (absorbance at $520 \mathrm{~nm}$ ) and brown (absorbance at $420 \mathrm{~nm}$ ) colour from the loss of polymeric pigment colour (PPC) (Fig 5(b)). Decreases in polymeric anthocyanins (TPA) in ports matured in oak casks were also observed with the decreases in PPC after 250 days of maturation (Fig 6(a)). However, TPA remained fairly constant throughout the maturation of ports in all containers, even though PPC increased. This suggests a shift in the ratio between polymeric pigments resistant to $\mathrm{SO}_{2}$ and the less resistant forms of pigments. Throughout the maturation of these ports, monomeric anthocyanins (TMA) decreased (Fig 6(b)) as the importance of the polymeric pigment contribution to colour
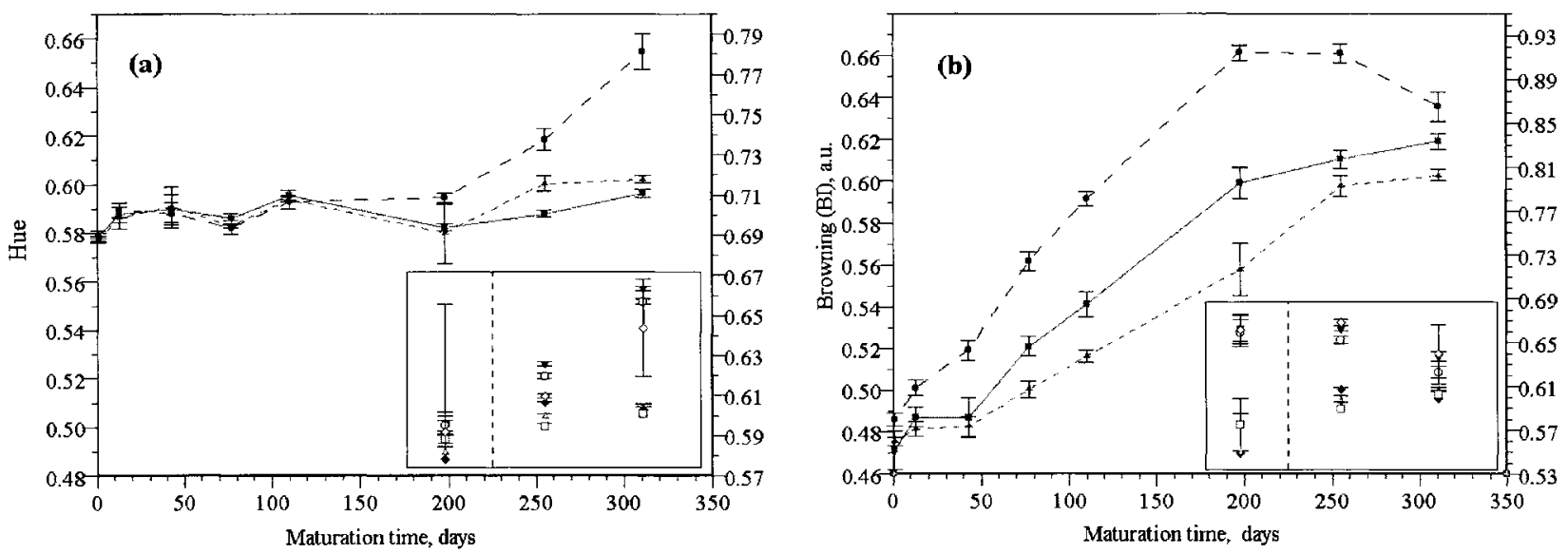

Figure 4. Changes in (a) hue and (b) browning during the maturation of port in oak (full circles), stainless steel (full triangles) and glass (full squares). Error bars show the $95 \%$ confidence interval of the mean. The insets show mean differences before racking and 1 and 3 months after racking for individual ports matured in oak casks and stainless steel tanks. The scale on the right-hand side of each graph is the scale for data in the inset. The vertical broken line denotes the time of racking. Individual ports are ports matured in oak casks and racked with forced aeration (full inverted triangles), racked with limited aeration (open diamonds) or not racked (open circles), and ports matured in stainless steel tanks and racked with forced aeration (full diamonds), racked with limited aeration (open triangles) or not racked (open squares). For ports matured in stainless steel, only positive error bars are shown. 

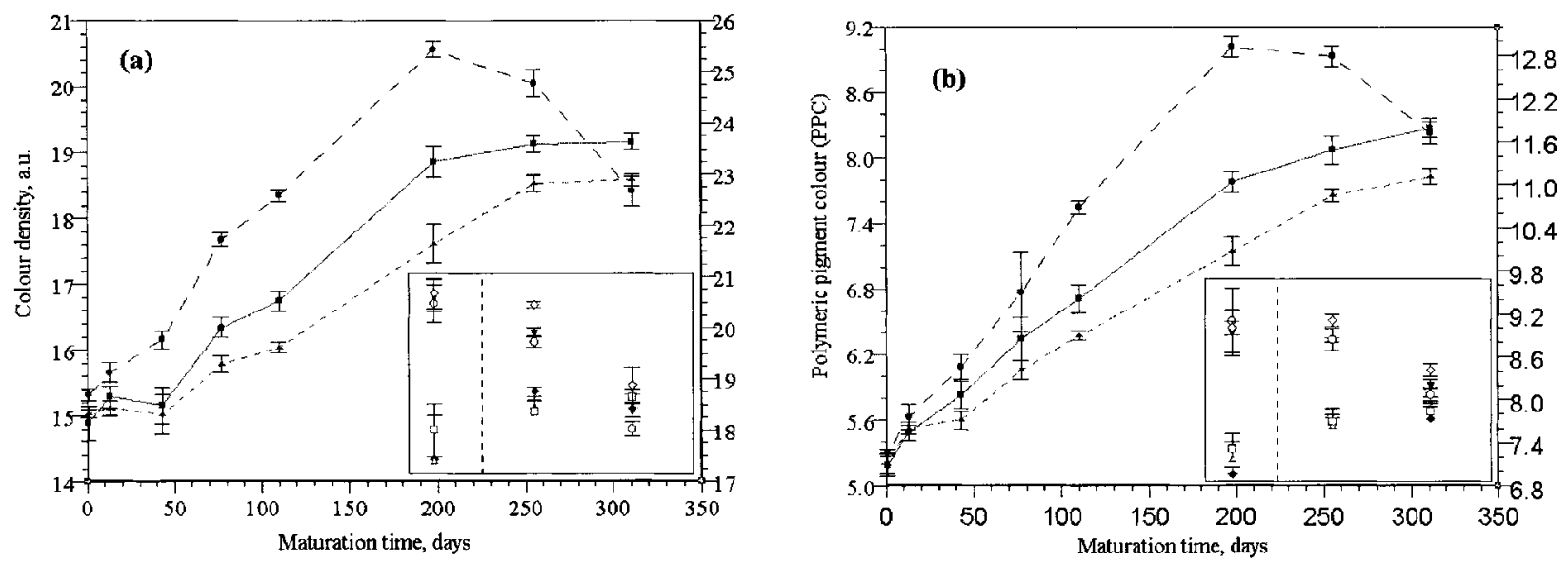

Figure 5. Changes in (a) colour density and (b) polymeric pigment colour during the maturation of port in oak (full circles), stainless steel (full triangles) and glass (full squares). Error bars show the $95 \%$ confidence interval of the mean. The insets show mean differences before racking and 1 and 3 months after racking for individual ports matured in oak casks and stainless steel tanks. The scale on the right-hand side of each graph is the scale for data in the inset. The vertical broken line denotes the time of racking. Individual ports are ports matured in oak casks and racked with forced aeration (full inverted triangles), racked with limited aeration (open diamonds) or not racked (open circles), and ports matured in stainless steel tanks and racked with forced aeration (full diamonds), racked with limited aeration (open triangles) or not racked (open squares). For ports matured in stainless steel, only positive error bars are shown.

increased (Fig 5(b)). An increase in the degree of pigment coloration $\left(A_{3.7}\right)$ with maturation further demonstrated the increasing contribution of polymeric pigments to wine colour ${ }^{24}$ (Fig 7a). Decreases in $\mathrm{pH}$ and free $\mathrm{SO}_{2}$, which can also affect $A_{3.7}$ values, might also have partly contributed to the increases observed. ${ }^{53}$ However, colour synergism $\left(S_{3.7}\right)$, which can be used to measure both co-pigmentation and selfassociation of pigments in wine,${ }^{24}$ increased in all ports during maturation (Fig 7(b)). Co-pigmentation can be affected by many factors, such as the type and concentration of anthocyanins, type and concentration of co-pigments, $\mathrm{pH}$ of the medium, temperature and the presence of various metals. ${ }^{56-58}$ Co-pigmentation might have increased during maturation owing to rearrangements or 're-stacking' of co-pigments, caused by temperature and severe changes in dielectric properties as a result of fortification (Boulton RB, personal communication). Co-pigmentation has been suggested as a first step in the formation of polymeric pigments during aging. ${ }^{5}$

Total phenolics was considered not to have changed significantly during maturation, as shown by its low negative loading on PC1 when considering changes during maturation time, although there was an initial increase in total phenolics after just 35 days, followed by a decrease before rising again by 255 days of maturation in all ports (Fig 8). Phenolic compounds in many different types of wines generally decrease during maturation..$^{30,31,59-61}$ Oxidation, condensation
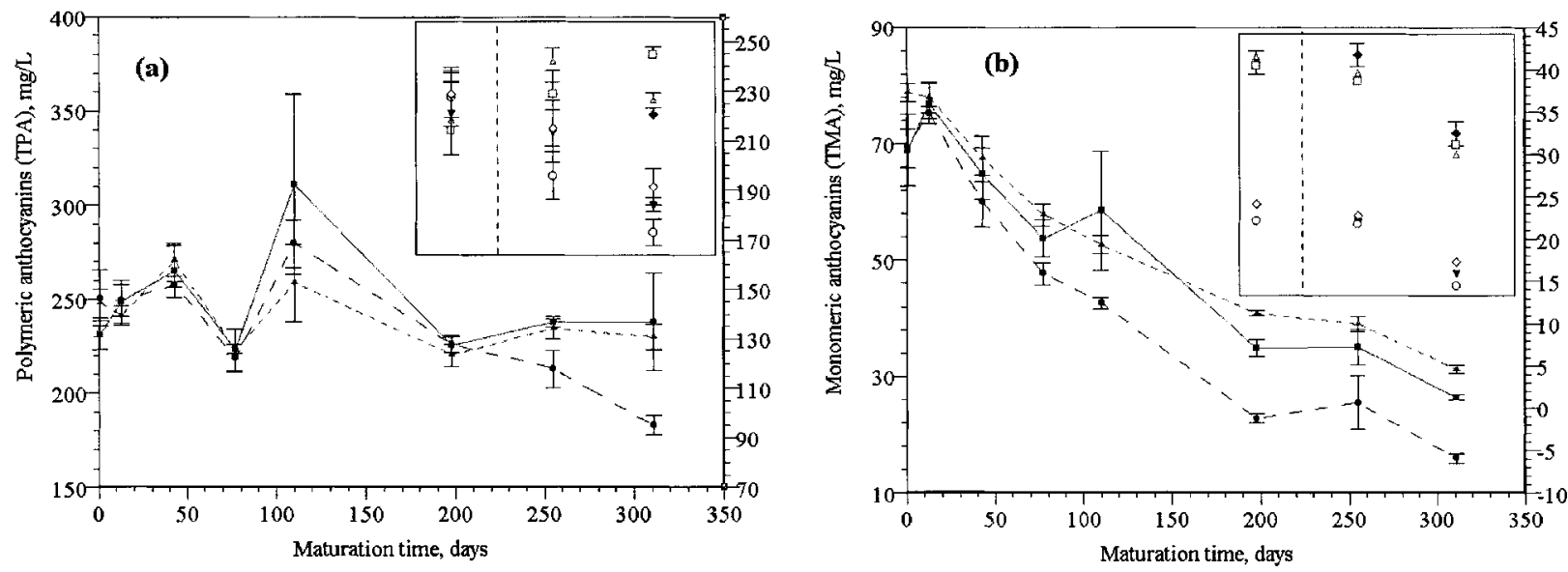

Figure 6. Changes in (a) total polymeric anthocyanins and (b) total monomeric anthocyanins during the maturation of port in oak (full circles), stainless steel (full triangles) and glass (full squares). Error bars show the 95\% confidence interval of the mean. The insets show mean differences before racking and 1 and 3 months after racking for individual ports matured in oak casks and stainless steel tanks. The scale on the right-hand side of each graph is the scale for data in the inset. The vertical broken line denotes the time of racking. Individual ports are ports matured in oak casks and racked with forced aeration (full inverted triangles), racked with limited aeration (open diamonds) or not racked (open circles), and ports matured in stainless steel tanks and racked with forced aeration (full diamonds), racked with limited aeration (open triangles) or not racked (open squares). For ports matured in stainless steel, only positive error bars are shown. 

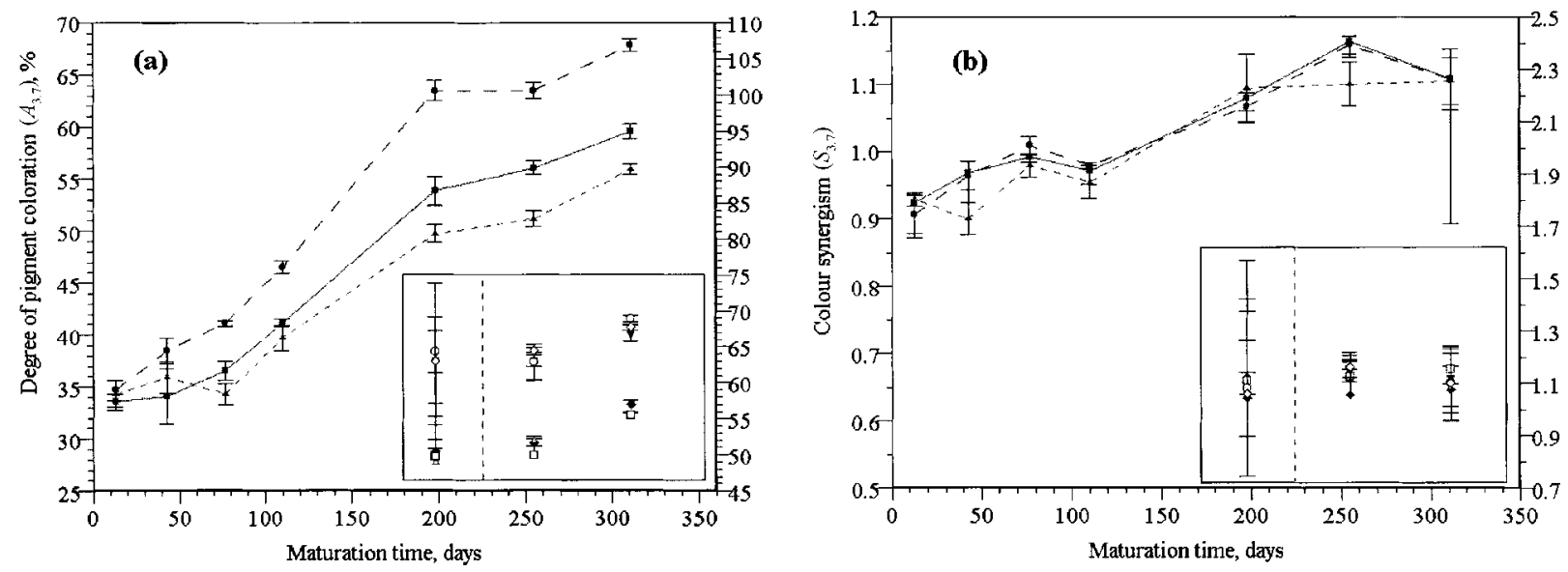

Figure 7. Changes in (a) degree of pigment coloration and (b) colour synergism during the maturation of port in oak (full circles), stainless steel (full triangles) and glass (full squares). Error bars show the 95\% confidence interval of the mean. The insets show mean differences before racking and 1 and 3 months after racking for individual ports matured in oak casks and stainless steel tanks. The scale on the right-hand side of each graph is the scale for data in the inset. The vertical broken line denotes the time of racking. Individual ports are ports matured in oak casks and racked with forced aeration (full inverted triangles), racked with limited aeration (open diamonds) or not racked (open circles), and ports matured in stainless steel tanks and racked with forced aeration (full diamonds), racked with limited aeration (open triangles) or not racked (open squares). For ports matured in stainless steel, only positive error bars are shown.

and polymerisation reactions eventually lead to the precipitation of tannins and pigments, thus lowering the total amount of phenolic compounds found in a matured wine. ${ }^{1,3,62}$ However, increases in phenolic compounds have been observed in wines during their aging without wood contact $^{63}$ and also in woodmatured Tawny ports. ${ }^{21,64}$ There were also noticeable differences in total phenolics (TPGAE) between ports matured in different containers. Ports aged in oak casks began to show higher total phenolics after 77 days of maturation, subsequently becoming signifi-

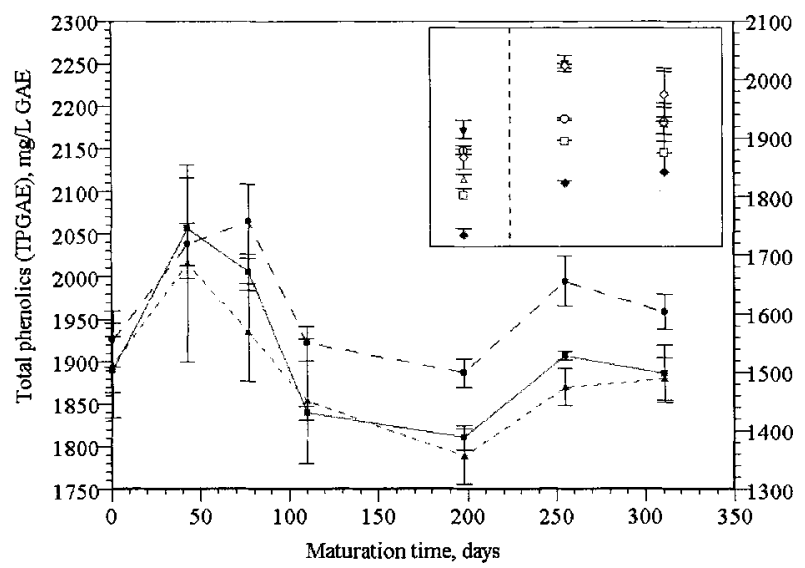

Figure 8. Changes in total phenolics during the maturation of port in oak (full circles), stainless steel (full triangles) and glass (full squares). Error bars show the $95 \%$ confidence interval of the mean. The inset shows mean differences before racking and 1 and 3 months after racking for individual ports matured in oak casks and stainless steel tanks. The scale on the righthand side of the graph is the scale for data in the inset. The vertical broken line denotes the time of racking. Individual ports are ports matured in oak casks and racked with forced aeration (full inverted triangles), racked with limited aeration (open diamonds) or not racked (open circles), and ports matured in stainless steel tanks and racked with forced aeration (full diamonds), racked with limited aeration (open triangles) or not racked (open squares). For ports matured in stainless steel, only positive error bars are shown. cantly different from total phenolic values measured in ports matured in stainless steel tanks and glass jars after 198 days. This difference in total phenolics in ports matured in oak casks may be accounted for by a concentration effect from evaporation losses as high as $8 \%$ after 220 days of maturation (Table 3)

Generally, there were differences in maturation between ports in oak casks and those in stainless steel tanks and glass jars, noticeable even after 13 days of maturation by the plot of $\mathrm{PC} 1$ scores versus maturation time (Fig 3(a)). This suggests that wood-matured ports developed at a faster rate than non-woodmatured ones. This was confirmed by the lower average value for the chemical age index CA(III) of approximately 0.24 for ports matured in oak casks compared to average values of 0.31 for ports matured in stainless steel tanks and 0.30 for ports matured in glass jars. The only clearly identifiable factor which could have accounted for the differences in maturation rate between these ports would have been the differences in redox potential and dissolved oxygen. Differences in the amount of initial dissolved oxygen and the frequency of aeration, which can increase the development rate of colour parameters, ${ }^{65}$ would have ultimately affected the relative maturation rate of these ports. There were also a general trend that ports matured in oak casks showed mostly positive PC3 scores while ports matured in stainless steel tanks and glass jars showed negative PC 3 scores after about 77 days of maturation (Fig 2(b)). The loadings plot suggests that this difference might be related to differences in total phenolics (TPGAE) and polymeric anthocyanins (TPA), the two highest positively loaded variables on $\mathrm{PC} 3$.

Racking with aeration after 224 days of maturation of ports in oak casks and stainless steel tanks seemed to result in only minor differences in some variables compared to ports that were not racked. Hue values 
Table 3. Redox potential, headspace volume and dissolved oxygen during the maturation of port

\begin{tabular}{|c|c|c|c|c|c|c|c|c|c|c|c|}
\hline \multirow[b]{3}{*}{ Parameter } & \multicolumn{11}{|c|}{ Time of maturation (before and after racking) } \\
\hline & \multicolumn{2}{|c|}{2 days before } & \multicolumn{2}{|c|}{1 month after } & \multicolumn{2}{|c|}{2 months after } & \multicolumn{2}{|c|}{3 months after } & \multicolumn{3}{|c|}{15 months after } \\
\hline & $E_{h}(10)^{a}$ & $\mathrm{H}_{\mathrm{vol}}$ & $\mathrm{E}_{h}(7)^{\mathrm{a}}$ & $\mathrm{H}_{\mathrm{vol}}$ & $\mathrm{E}_{h}(7)^{\mathrm{a}}$ & $\mathrm{H}_{\mathrm{vol}}$ & $\mathrm{E}_{h}(8)^{\mathrm{a}}$ & $\mathrm{H}_{\mathrm{vol}}$ & $\mathrm{E}_{h}(6)^{\mathrm{a}}$ & $\mathrm{O}_{2}(6)^{\mathrm{a}}$ & $\mathrm{H}_{\mathrm{vol}}$ \\
\hline $\mathrm{B} \times \mathrm{FAR}$ & $183 \pm 9$ & 2.00 & $190 \pm 7$ & 3.00 & $185 \pm 2$ & - & $187 \pm 2$ & 3.50 & $145 \pm 2$ & $1.2 \pm 0.04$ & 6.00 \\
\hline$B \times L A R$ & $186 \pm 9$ & 3.50 & $183 \pm 6$ & 4.00 & $184 \pm 3$ & - & $183 \pm 2$ & 4.60 & $137 \pm 4$ & $1.2 \pm 0.05$ & 9.00 \\
\hline$B \times N R$ & $181 \pm 9$ & 3.00 & $185 \pm 6$ & 3.00 & $179 \pm 2$ & - & $183 \pm 2$ & 3.40 & $137 \pm 6$ & $1.7 \pm 0.09$ & 5.50 \\
\hline $\mathrm{T} \times \mathrm{FAR}$ & $55 \pm 3$ & 0.19 & $96 \pm 2$ & 0.25 & $99 \pm 2$ & - & $112 \pm 2$ & 0.26 & $119 \pm 2$ & $0.7 \pm 0.04$ & 0.32 \\
\hline$T \times L A R$ & $76 \pm 4$ & 0.13 & $152 \pm 3$ & 0.29 & $106 \pm 3$ & - & $103 \pm 2$ & 0.29 & $77 \pm 2$ & $0.5 \pm 0.05$ & 0.31 \\
\hline $\mathrm{T} \times \mathrm{NR}$ & $96 \pm 4$ & 0.18 & $102 \pm 3$ & 0.18 & $97 \pm 2$ & - & $102 \pm 4$ & 0.20 & $110 \pm 1$ & $0.6 \pm 0.05$ & 0.32 \\
\hline
\end{tabular}

$\mathrm{B}$, oak casks; $\mathrm{T}$, stainless steel tanks; FAR, racking with forced aeration; LAR, racking with limited aeration; NR, not racked; $E_{\mathrm{h}}$, redox potential (mV); $H_{\text {vol }}$, headspace volume $(\mathrm{I}) ; \mathrm{O}_{2}$, dissolved oxygen $\left(\mathrm{mg} \mathrm{I}^{-1}\right)$.

a Number of replicate measurements in parentheses for calculating the standard error of the mean.

were different in all ports matured in oak casks and stainless steel tanks, but no significant differences were noted between any of these wines at the end of 311 days of maturation (Fig 4(a)). Colour density and browning were slightly different for ports matured in oak casks that were racked compared to the one which was not 1 month after racking (Figs 4(b) and 5(a)). However, after 311 days of maturation, no differences were detected in browning, and only colour density in ports matured in oak casks that were racked was different from the non-racked port. Colour density and browning seemed to be unaffected by racking in ports matured in stainless steel tanks. Polymeric pigment colour decreased at a slightly faster rate for both racked ports matured in oak casks, but was unaffected in ports matured in stainless steel tanks (Fig 5(b)). However, racking affected polymeric anthocyanins more in ports matured in stainless steel tanks than in those matured in oak casks (Fig 6(a)). Small differences were also found between ports that were racked and those that were not in the degree of pigment coloration and monomeric anthocyanins, with no noticeable effect on total phenolics after 311 days of maturation (Figs 6(b), 7(a) and 8). Colour synergism (Fig 7(b)) and all chemical age indices did not seem to be affected by racking. From these results, no conclusions can be made as to whether racking with aeration has an effect on the changes in colour and phenolic composition in port maturation.

\section{CONCLUSIONS}

Changes in colour and phenolic composition during the maturation of port in wood, stainless steel and glass have been examined, aided by the use of principal component analysis. Ports in oak casks matured at a faster rate than those in either stainless steel tanks or glass jars. Oxygen was considered to be an important factor affecting the evolution of colour and phenolic composition in port maturation. Further studies should be undertaken to examine the role of oxygen in relation to other environmental factors affecting port maturation. Racking, which results in wine aeration, may also be an important parameter in controlling the rate of port maturation and therefore also needs to be examined further.

\section{ACKNOWLEDGEMENTS}

The authors gratefully acknowledge Ramos-Pinto, Lda for providing the port and the oak casks. Peter Ho was financed by a PRAXIS XXI grant (BD/13825/ 97) from the Fundação para a Ciência e a Technologia (FCT).

\section{REFERENCES}

1 Jurd L, Review of polyphenol condensation reactions and their possible occurrence in the ageing of wines. Am $\mathcal{F}$ Enol Vitic 20:191-195 (1969).

2 Bakker J and Timberlake CF, The mechanism of color changes in aging port wine. Am f Enol Vitic 37:288-292 (1986).

3 Ribéreau-Gayon P and Glories Y, Phenolics in grapes and wines, in Proceedings of the Australian Wine Industry Technical Conference, Ed by Lee T, Australian Industrial Publishers, Adelaide, pp 267-271 (1987).

4 Liao H, Cai Y and Haslam E, Polyphenol interactions. Anthocyanins: co-pigmentation and colour changes in red wines. $\mathcal{F}$ Sci Food Agric 59:299-305 (1992).

5 Brouillard R and Dangles O, Anthocyanin molecular interactions: the first steps in the formation of new pigments during wine aging? Food Chem 51:364-371 (1994).

6 Bakker J, HPLC of anthocyanins in port wines: determination of ageing rates. Vitis 25:203-214 (1986).

7 La Notte E, Liuzzi VA and Esti M, I componenti polifenolici del vino. Note III. I pigmenti polimerici. Vigne Vini 20:75-78 (1993).

8 Dallas C, Ricardo-da-Silva JM and Laureano O, Degradation of oligomeric procyanidins and anthocyanins in a Tinta Roriz red wine during maturation. Vitis 34:51-56 (1995).

9 Waters EJ, Peng Z, Pocock KF, Jones GP, Clark P and Willians PJ, Solid-state ${ }^{13} \mathrm{C}$ NMR investigation into insoluble deposits adhering to the inner glass surface of bottled red wine. F Agric Food Chem 42:1761-1766 (1994).

10 Cameira-dos-Santos PJ, Brillouet JM, Cheynier V and Moutounet $M$, Detection and partial characterisation of new anthocyanin-derived pigments in wine. F Sci Food Agric 70:204-208 (1996).

11 Bakker $\mathrm{J}$ and Timberlake CF, Isolation, identification and characterization of new color-stable anthocyanins occurring in some red wines. F Agric Food Chem 45:35-43 (1997).

12 Saucier C, Little D and Glories Y, First evidence of acetaldehyde-flavanol condensation products in red wine. Am $\mathcal{F}$ Enol Vitic 48:370-373. 
13 Bakker J and Timberlake CF, An analytical method for defining a tawny port wine. Am $\mathcal{F}$ Enol Vitic 36:252-253 (1985).

14 Bakker J, Bridle P and Timberlake CF, Tristimulus measurements (CIELAB 76) of port wine colour. Vitis 25:67-78 (1986).

15 Bakker J, Picinelli A and Bridle P, Model wine solutions: colour and compositional changes during ageing. Vitis 32:111-118 (1993).

16 Dallas C, Ricardo-da-Silva JM and Laureano O, Interactions of oligomeric procyanidins in model wine solutions containing malvidin-3-glucoside and acetaldehyde. I Sci Food Agric 70:493-500 (1996).

17 Francia-Aricha EM, Rivas-Gonzalo JC and Santos-Buelga C, Effect of malvidin-3-monoglucoside on the browning of monomeric and dimeric flavanols. $Z$ Lebensm Untersuch Forsch $A$ 207:223-228 (1998).

18 Bakker J, Bridle P, Timberlake CF and Arnold GM, The colours, pigment and phenol contents of young port wines. Vitis 25:4052 (1986).

19 Bakker J, Preston NW and Timberlake CF, The determination of anthocyanins in aging red wines: comparison of HPLC and spectral methods. Am F Enol Vitic 37:121-126 (1986).

20 Bakker J, Bellworthy SJ, Hogg TA, Kirby RM, Reader HP, Rogerson FSS, Watkins SJ and Barnett JA, Two methods of port vinification: a comparison of changes during fermentation and of characteristics of the wines. Am $\mathcal{F}$ Enol Vitic 47:37-41 (1996).

21 Ho P and Silva MCM, Changes in the phenolic composition of tawny port during wood ageing, in Proceedings of the Tenth Australian Wine Industry Technical Conference, Ed by Blair RJ, Sas AN, Hayes PF and Høj PB, Winetitles, Adelaide, p 259 (1999).

22 Somers TC and Evans ME, Spectral evaluation of young red wines: anthocyanin equilibria, total phenolics, free and molecular $\mathrm{SO}_{2}$, 'chemical age'. F Sci Food Agric 28:279-287 (1977).

23 Jackson MG, Timberlake CF, Bridle P and Vallis L, Red wine quality: correlations between colour, aroma and flavour and pigment and other parameters of young Beaujolais. F Sci Food Agric 29:715-727 (1978).

24 Somers TC and Vérette E, Phenolic composition of natural wine types, in Modern Methods of Plant Analysis. Vol 6. Wine Analysis. Ed by Linskins HF and Jackson JF, Springer, New York, pp 219-257 (1988).

25 González L, Pérez-Zúñiga FJ and Bravo F, Color measurements in fermented beverages and derivatives: wines, beers, and brandies. Alimentaria (216):59-67 (1990).

26 Echávarri JF, Ayala F, Figueira $\mathrm{AR}$ and Negueruela AI, Colorimetry in port wines. Food Sci Technol Int 2:375-382 (1996).

27 Ayala F, Echávarri JF and Negueruela AI, A new simplified method for measuring the color of wines. I. Red and rosé wines. Am f Enol Vitic 48:357-363 (1997).

28 Ayala F, Echávarri JF and Negueruela AI, A new simplified method for measuring the color of wines. II. White wines and brandies. Am $\mathcal{F}$ Enol Vitic 48:364-369 (1997).

29 Negueruela AI, Echávarri JF and Pérez MM, A study of correlation between enological colorimetric indexes and CIE colorimetric parameters in red wines. Am $\mathcal{F}$ Enol Vitic 46:353356 (1995).

30 Somers TC and Evans ME, Evolution of red wines. I. Ambient influences on colour composition during early maturation. Vitis 25:31-39 (1986)

31 Gómez-Cordovés C and González-SanJosé ML, Interpretation of color variables during the ageing of red wines: relationship with families of phenolic compounds. I Agric Food Chem 43:557-561 (1995)

32 Ho P, Silva MCM and Hogg TA, Multiple imputation and maximum likelihood principal component analysis of incomplete multivariate data from a study of the ageing of port. Chemometrics Intell Lab Syst 55:1-11 (2001).
33 Mayson R, Port and the Douro. Faber and Faber, London (1999). 34 Vivas $\mathrm{N}$ and Glories Y, Racking of red wines matured in barrels. A tentative classification of racking techniques. Aust NZ Wine Ind f 10:241-243 (1995).

35 Vivas $\mathrm{N}$ and Glories Y, Étude du soutirage des vins rouges élevés en barriques. Essai de classification des différentes techniques de soutirage. Prog Agric Vitic 111:421-424 (1994).

36 Sudraud P, Interprétation des courbes d'absortion des vins rouges. Ann Technol Agric 7:203-208 (1958).

37 Glories Y, La couleur des vins rouges. 2 Partie. Mesure, origine et interprétation. Connais Vigne Vin 18:253-271 (1984).

38 Bakker J and Arnold GM, Analysis of sensory and chemical data for color evaluation of a range of red port wines. Am F Enol Vitic 44:27-34 (1993).

39 Oszmianski J, Ramos $\mathrm{T}$ and Bourzeix M, Fractionation of phenolic compounds in red wine. Am F Enol Vitic 39:259-262 (1988).

40 Jaworski AW and Lee CY, Fractionation and HPLC determination of grape phenolics. F Agric Food Chem 35:257-259 (1987).

41 Niketić-Aleksić GK and Hrazdina G, Quantitative analysis of the anthocyanin content in grape juices and wines. Lebensm Wiss Technol 5:163-165 (1972).

42 Schafer JL and Olsen MK, Multiple imputation for multivariate missing-data problems: a data analyst's perspective. Multivariate Behav Res 33:545-571 (1998).

43 Schafer JL, NORM: multiple imputation of incomplete multivariate data under a normal model, version 2 . Software for Windows 95/98/NT Online. Available: http://www.stat.psu. edu/ jls/misoftwa.html (1998).

44 Ihaka $\mathrm{R}$ and Gentleman R, R: a language for data analysis and graphics. F Comput Graph Statist 5:299-314 (1996).

45 Dallas $\mathrm{C}$ and Laureano O, Effect of $\mathrm{pH}$, sulphur dioxide, alcohol content, temperature and storage time on colour composition of a young Portuguese red table wine. I Sci Food Agric 65:477485 (1994).

46 Gonzales Cartagena L, Perez-Zuñiga FJ and Bravo Abad F, Interactions of some environmental and chemical parameters affecting the colour of wine. Am F Enol Vitic 45:43-48 (1994).

47 Sims CA and Morris JR, A comparison of the color components and color stability of red wine from Noble and Cabernet Sauvignon at various $\mathrm{pH}$ levels. Am $\mathcal{F}$ Enol Vitic 36:181-184 (1985).

48 García-Viguera C, Bridle $\mathrm{P}$ and Bakker J, The effect of $\mathrm{pH}$ on the formation of coloured compounds in model solutions containing anthocyanins, catechins and acetaldehyde. Vitis 33:37-40 (1994).

49 Heredia FJ, Francia-Aricha EM, Riva-Gonzalo JC, Vicario IM and Santos-Buelga C, Chromatic characterization of anthocyanins from red grapes-I. pH effect. Food Chem 63:491-498 (1998).

50 Picinelli A, Bakker J and Bridle P, Model wine solutions: effect of sulphur dioxide on colour and composition changes during ageing. Vitis 33:31-35 (1994).

51 Somers TC and Wescombe LG, Red wine quality. The critical role of $\mathrm{SO}_{2}$ during vinification and conservation. Aust Grapegrower Winemaker (220):68-74 (1982).

52 Somers TC and Wescombe LG, Evolution of red wines. II. An assessment of the role of acetaldehyde. Vitis 26:27-36 (1987).

53 Somers TC, The Wine Spectrum: an Approach towards Objective Definition of Wine Quality. Winetitles, Adelaide (1988).

54 Ribéreau-Gayon P, Pontallier P and Glories Y, Some interpretations of colour changes in young red wines during their conservation. I Sci Food Agric 34:505-516 (1983).

55 Piggot JR and Sharman K, Methods to aid interpretation of multidimensional data, in Statistical Procedures in Food Research, Ed by Piggot JR, Elsevier Applied Science, Barking, pp 181-232 (1986).

56 Mazza G and Brouillard R, The mechanism of co-pigmentation of anthocyanins in aqueous solutions. Phytochemistry 29:10971102 (1990).

57 Maccarone E, Dugo $\mathrm{P}$ and Passerini A, Effects of phenolic 
copigments on the flavylium-chromenol equilibrium of anthocyanins. Ital F Food Sci 4:247-258 (1992).

58 Davies AJ and Mazza G, Copigmentation of simple and acylated anthocyanins with colorless phenolic compounds. $\mathcal{F}$ Agric Food Chem 41:716-720 (1993).

59 Archier P, Coen S and Roggero JP, Composition phénolique de vins issus de moncépages. Sci Alim 12:453-466 (1992).

60 Moretti S, Evoluzione dei composti fenolici e loro influenza sulle caratteristiche organolettiche dei vini. Vini Ital 34:49-58 (1992).

61 Mayén M, Mérida $J$ and Medina M, Flavonoid and nonflavonoid compounds during fermentation and post-fermentation standing of musts from Cabernet Sauvignon and Tempranillo grapes. Am $\mathcal{F}$ Enol Vitic 46:255-261 (1995).
62 Haslam E, In vino veritas: oligomeric procyanidins and the ageing of red wines. Phytochemistry 19:2577-2582 (1980).

63 Archier P, Coen S and Roggero J-P, Changes in the phenolic content of single-variety wines after the first nine months of storage. Sci Alim 13:483-489 (1993).

64 Ho P, Hogg TA and Silva MCM, Application of a liquid chromatographic method for the determination of phenolic compounds and furans in fortified wines. Food Chem 64:115122 (1999).

65 Pontallier P and Ribéreau-Gayon P, Influence de l'aération et du sulfitage sur l'évolution de la matière colorante des vins rouges au cours de la phase d'élevage. Connaiss Vigne Vin 17:105-120 (1983). 